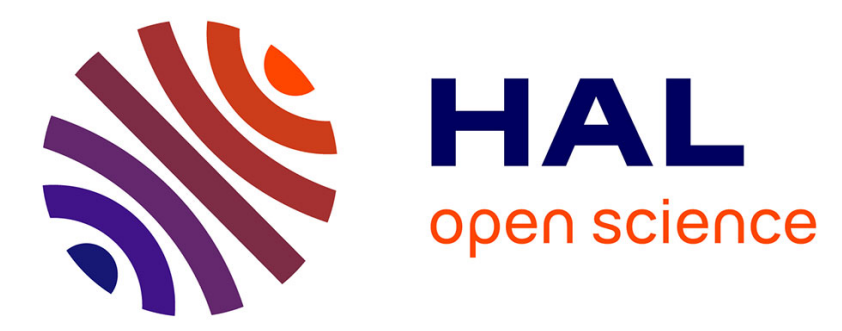

\title{
MElba Mediterranean lagrangian buoy appliance
}

Fiorello Cavallini, Daniele Maffei, Ramiro Dell'Erba

\section{To cite this version:}

Fiorello Cavallini, Daniele Maffei, Ramiro Dell'Erba. MElba Mediterranean lagrangian buoy appliance. Oceans 2001 MTS/IEEE, Nov 2001, Honolulu, HI, United States. hal-02006978

\section{HAL Id: hal-02006978 \\ https://hal.science/hal-02006978}

Submitted on 5 Feb 2019

HAL is a multi-disciplinary open access archive for the deposit and dissemination of scientific research documents, whether they are published or not. The documents may come from teaching and research institutions in France or abroad, or from public or private research centers.
L'archive ouverte pluridisciplinaire HAL, est destinée au dépôt et à la diffusion de documents scientifiques de niveau recherche, publiés ou non, émanant des établissements d'enseignement et de recherche français ou étrangers, des laboratoires publics ou privés. 


\section{ENEA}

Italian National Agency for New Technologies, Energy and Sustainable Economic Development

http://www.enea.it/en

http://robotica.casaccia.enea.it/index.php?lang=en

This paper is a pre-print. The final paper is available on:

Acta congress all' "Oceans 2001 MTS/IEEE", Honolulu 5-8

novembre 2001, intitolato: "MElba Mediterranen lagrangian buoy appliance". 


\title{
MELBA MEditerranean Lagrangian Buoy Appliance
}

\author{
Fiorello Cavallini - Daniele Maffei - Ramiro dell'Erba \\ Italian National Agency for New Technology, Energy and Environment (ENEA) \\ Division of Robotics and Information Technology \\ Centro Ricerche Casaccia, \\ Via Anguillarese, 301 , I 00060 Roma
}

\begin{abstract}
The MEditerranean Lagrangian Buoy Appliance project (MELBA) is a project oriented towards the realisation of an instrument (buoy) for the specific conformation of the Mediterranean area, which presents restricted spatial dimensions in many cases associated to a high variability of the sea-depth.

The dynamic of the body-of-water flux, in the Mediterranean area, is affected by the deep-sea and coastal line high variability.

The MELBA project purpose is the realisation of a profiling drifter, dedicated to the Mediterranean environment. The control system is improving taking into account the above considerations, for long and medium term missions, but also for very short, repetitive, coastal missions that are dedicated to short time and space scale biological, ecological or anti-pollution studies.

The carrier is formed by a pressure hull containing the instrumentation, by the engine for the vertical moving, by the electronic control system for the mission handling and for the emergency system.

The carrier is the base system for all mission typology. The only variation is to change the sensors and the relative data acquisition system for the specific mission.

The provided communication system is a double way satellite channel. A Global Position System (GPS) will support this system. The GPS use is essential to the data geo-reference and to have the exact buoy position for all emersion and transmission of data.

One of the most important features of MELBA buoy can be outlined in the control system. The control system is responsible for the realisation of the programmed mission.
\end{abstract}

\section{KEYWORDS: Drifter, Buoy, Lagrangian Float}

\section{BACKGROUND}

The Italian Ministry of Education, University and Scientific and Technological Research (MIUR) has pointed Italian National Agency for New Technology, Energy and Environment (ENEA) as executive Organization for research project to tune up the instrument for Mediterranean knowledge.

\section{INTRODUCTION}

The MELBA (MEditerranean Lagrangian Buoy Appliance) project is a project oriented towards the realisation of an instrument (buoy) for the specific conformation of the Mediterranean area, which presents restricted spatial dimensions in many cases associated to a high variability of the sea-depth.
We have therefore to operate in different conditions for the Mediterranean area, in which the ratio between the coast's conformation and the marine area's dimensions, surrounded by them, is absolutely not comparable to the Ocean's situation.

The dynamic of the body-of-water flux, in the Mediterranean area, is affected by the deep-sea and coastal line high variability. This is the cause that induces significant variations in the body-of-water direction within few tens of miles, or vortex.

As our study concerns the robotic appliance for study the environmental pollution's phenomena, we have to focus our attention towards the coastal areas as well as the entire areas heavy influenced by human activities.

One instrumental apparatus realised for the Mediterranean area implies a spatial and temporal measurement's scale as well as immersion drift times, fitting with the specific one of the phenomena we have to investigate on. For example high sample's frequency for the characterisation of the body-ofwater shifting in areas with rapidly variable morphology, have to be possible.

One of the MELBA system activities will be the high frequency sampling (per hour too) in the photic zone. This in order to study the case in which the phenomena of the adrift planktonic mass's evolution has to be reconstructed.

\section{A. Drifter}

The lagrangian drifters, either surface drifters or, as in the last years, the so called profiling drifters, are able to sink at a predefined depth, to trace deep currents and to get back to the surface and collecting data and transmitting them at shore. The use of such instruments has opened wider horizons to the oceanography, as well as climatic research in the oceans.

The time and space scale, as well as the dynamic of the phenomena to be investigated, are ideal for these instruments, and the cost is incomparable with the same activity conducted by standard methods.

\section{B. Specific of Mediterranean Sea}

The application of such technology in closed seas, like the Mediterranean areas, where time and space scales are often restricted, and where the dynamic shows very high gradients, due to bottom and coastal structure, requires the development of intelligence in the systems. This could be very useful in order to programming and reprogramming the mission's 


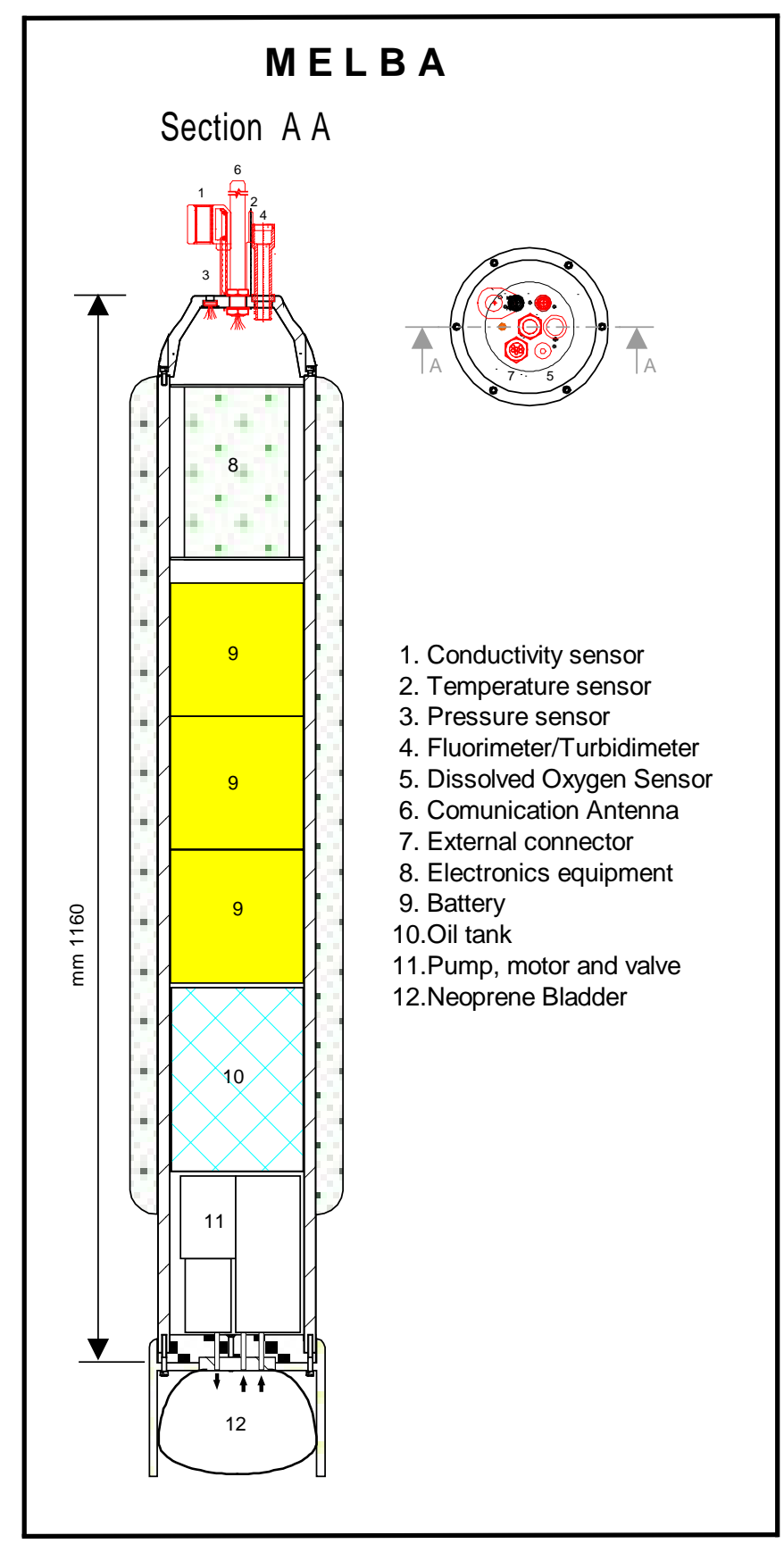

Fig. 1. The MELBA buoy

activities as well as the realisation of effective escape procedures, to avoid the drifters to be trapped in coastal bottom.

\section{MELBA}

The MELBA project purpose is the realisation of a profiling drifter, dedicated to the Mediterranean environment. The control system is improving taking into account the above considerations, for long and medium term missions, but also for very short, repetitive, coastal missions that are dedicated to short time and space scale biological, ecological or anti-pollution studies.

The profiling drifter (shown in Fig. 1) dedicated to the Mediterranean Sea will be able to work until 2000 meter.

The project is organised in four functional blocks for the buoy and one more for human interface. Each blocks will be implemented separately and then will be connected each other. The buoy structure is described in the follow blocks:
A. Carrier
B. Battery
C. Sensors
D. Electronics on board
E. Human Computer Interface

\section{A. Carrier}

The carrier is formed by a pressure hull containing the instrumentation, by the engine for the vertical moving, by the electronic control system for the mission handling and for the emergency system.

The carrier is the base system for all mission typology. The only variation is to change the sensors and the relative data acquisition system for the specific mission.

The pressure hull is improving with design technique such as aeronautic one. The use of such technology is in order to reduce the weight of the hull and to increase the load.

\section{B. Battery}

A considerable part of carrier's load is the battery pack.

The battery pack must be planned for the whole buoy's life (200 cycles).

The battery pack will be realised by the union, as in parallel as in series, of lithium cells (72) of height capacity (16,5 Ah 3,6 V)

\section{Sensors}

On the MELBA carrier it will be possible to load several typology of heads equipped with base sensors as C, T, D, (Conductivity, Temperature, Depth pressure) and with other sensors for the Dissolved Oxygen $\left(\mathrm{O}_{2}\right)$, Turbidity and Fluorescence measurements.

The system will be designed open to the realisation of the several sensors equipment, as for specific use in the Mediterranean Sea as for the actual use in the oceans systems.

\section{Electronic on board}

The electronic on board consists:
D1. Communication system
D2. Control system
D3. Data acquisition

\section{D1. Communication system}

The provided communication system is a double way satellite channel. A GPS as shown in Fig. 2 will support this system. The GPS use is essential to the data geo-reference and to have the exact buoy position for all emersion and transmission of data. 


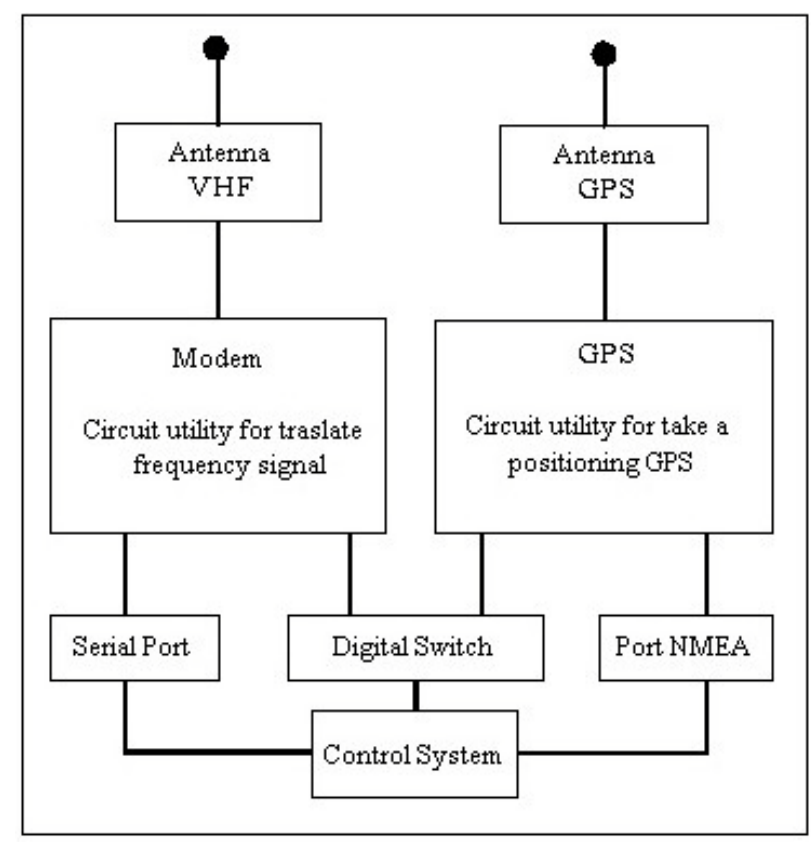

Fig. 2. Logical scheme of communication hardware

For this specific communication system it is developing an antenna right as to receive a GPS data as to transmit and receive from the satellite.

Another essential characteristic of this antenna is that its characteristics must be maintained in order to resist at the maximum pressures for all the buoy lifetime.

The hardware consists of a satellite modem card with a GPS on board.

The logic scheme of the software for the modem handling and control is shown in Fig. 3. This software will be a task of the control system of the buoy.

\section{D2. Control System}

The buoy is able to perform measurements in hydrology, chemical, biological and geological oceanography.

However it must be stressed some peculiarities to distinguish the needs for a buoy operating in the Mediterranean area. The main differences, with respect to the ocean exploration, is the higher variability of the sea bottom and of the coast pattern, producing vortex leading to a higher density of the grid measurements.

One of the most important features of MELBA buoy can be outlined in the control system. The control system is responsible for the realisation of the programmed mission. In spite of the elementary movement allowed to the buoy, which only can go up and down, we try to implement a more sophisticated control system.

We would like the buoy be able to follow a pattern (in some range) not only according to a programmed depth profile but also according to some other parameters. As example the control system should be able to keep the buoy at constant temperature moving it up and down to follow an isothermal pattern.

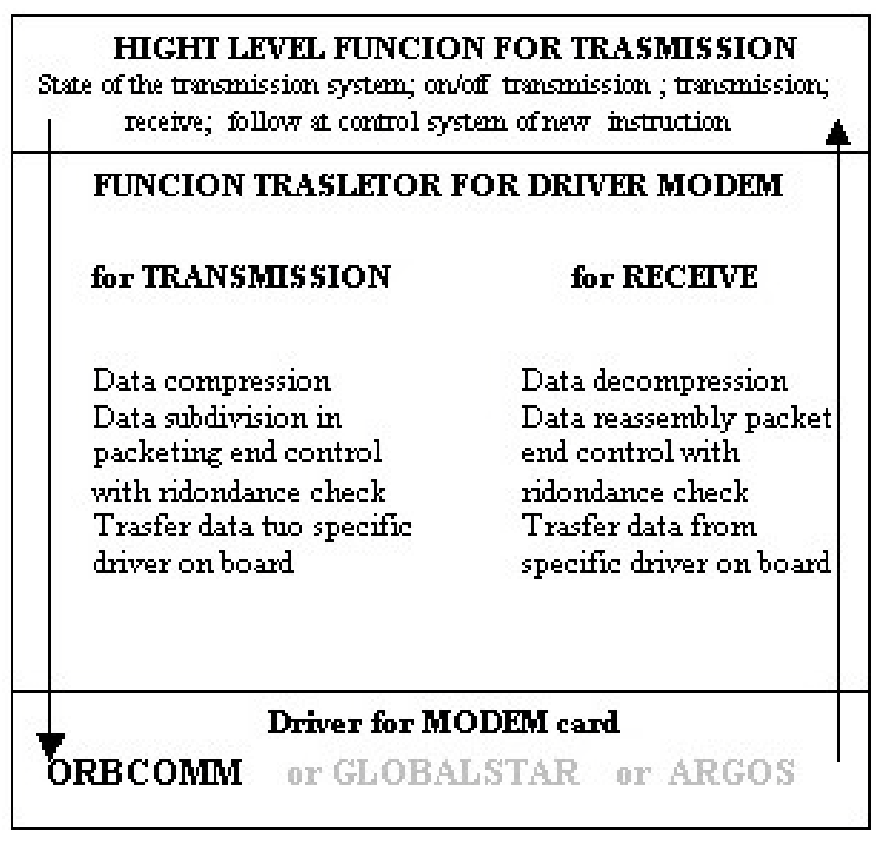

Fig. 3. The logic scheme of the software for modem

Moreover the control system should be able to take some elementary decision in case of non-vital failure like bad data transmission or anomalous electrical absorption from one user. Actual drifters are totally passive in transmission so many data are missing. In the other example the excessive adsorbing of one or more user from the battery pack can lead the control system to decide to isolate the user and continue the mission without that sensor. Practically there is the possibility to change the parameters of the mission in the meanwhile of the performance because of supervisor system. In case of failure of some instruments, as example, the mission will be partially re-planned to carry out a reduced mission optimising the performance. Our intention is to start by a simple method the rule based solutions and to increase progressively in complexity. Practically we want to start by a rule table like "If...Then" for the decision to assume or to ask for human help, thank to the bi-directional communication system. .

A logical scheme of the control system and its connections are shown in Fig. 4.

Particularly we can distinguish the logical units:

Scheduling

The scheduling task is to divide the received mission in simple tasks sequence and pass them to the monitor. The scheduling task receives from the monitor the new planned mission.

\section{Monitor}

The monitor receives the scheduled mission and sends the command to the scientific sensors and the navigation plan to the navigator system, which returns its navigation state. 


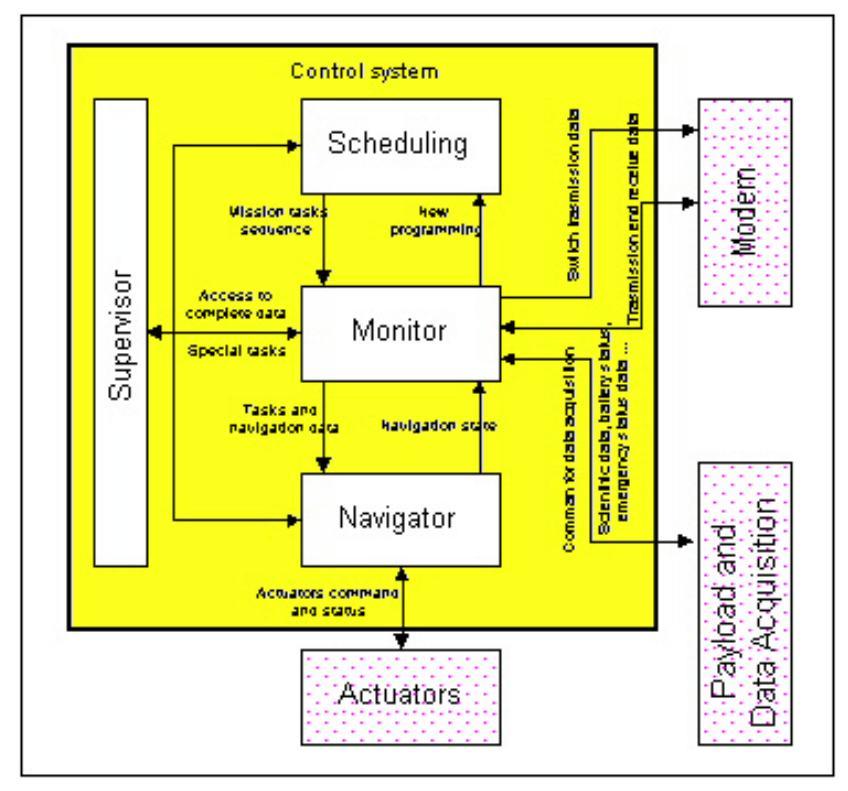

Fig. 4. Logical scheme of control system

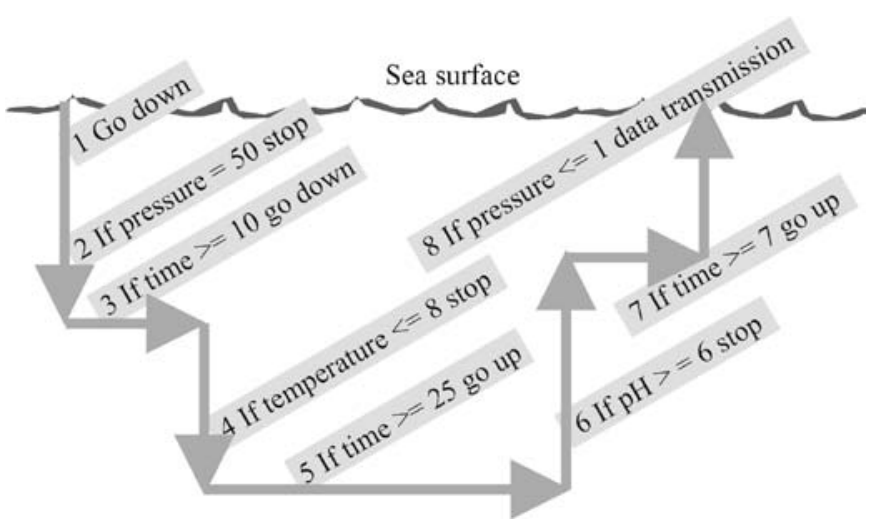

Fig. 5. The Visual Design Environment (VDE) of MELBA. Each arrow and vertex is a graphic command

The monitor also stores the scientific data and controls the data transmission.

\section{Navigation system}

The navigation system receives the plan from the monitor and informs it on the navigation state. The navigation system also sends elementary tasks to the actuators, receiving the feedback.

\section{Supervisor}

The supervisor is informed about all data and decides to follow an elementary rule-table, like "If ...Then" or in difficult case decides to ask for human work.

\section{D3. Data acquisition}

In order to make more flexible the buoy, it has been decided, during the design phase, to put a micro controller for conditioning and control of all sensors on board.

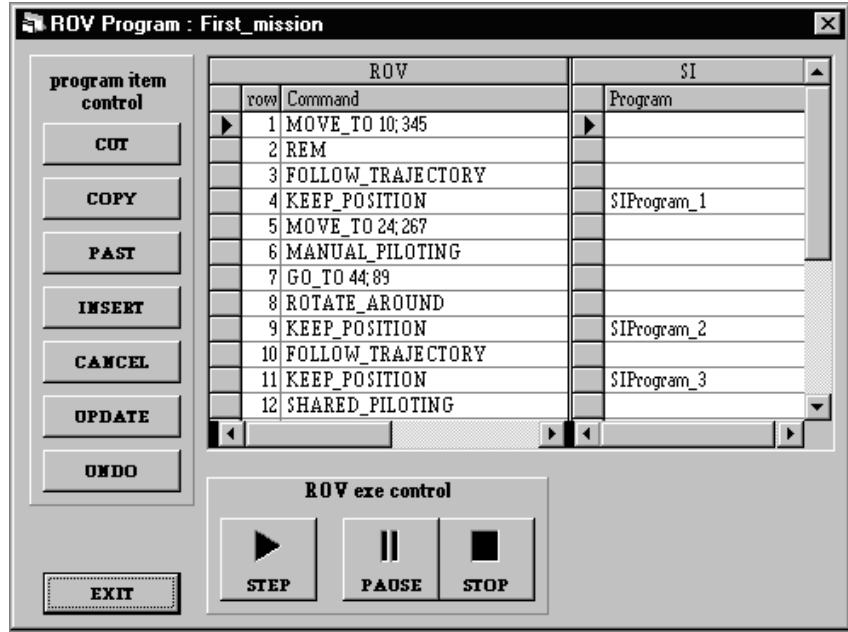

Fig. 6. The Integrated Development Environment (IDE) for ROV (and buoy) programming

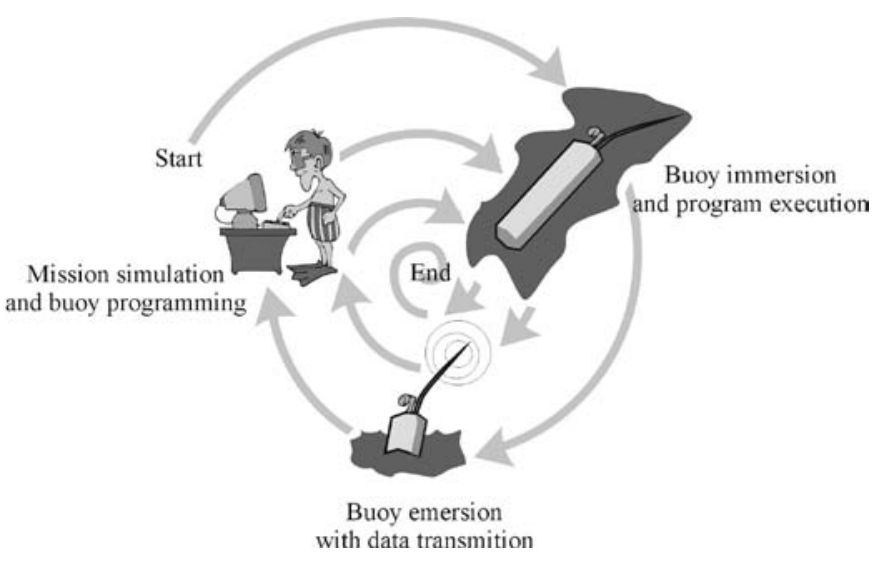

Fig. 7. The life cycle of buoy mission programming

The micro controller is also able to perform the first congruity level of the measured data and to control the sensors state.

\section{E. The Human Computer Interface and the mission programming}

The Melba's HCI takes full advantage of the experienced carried out with ARAMIS project. The MELBA buoy is a sophisticated drifter that needs to be programmed before and during the mission. To help the pilot/scientist in his task it is used a language visual like that made for the ARAMIS ROV. Naturally the set of commands adopted for the linguistic programming has been typify for a drifter that can move itself only vertically, and it is formed by:

- movement statements (as "go up”, "go down”, “stop”) to pilot up and down the buoy; 


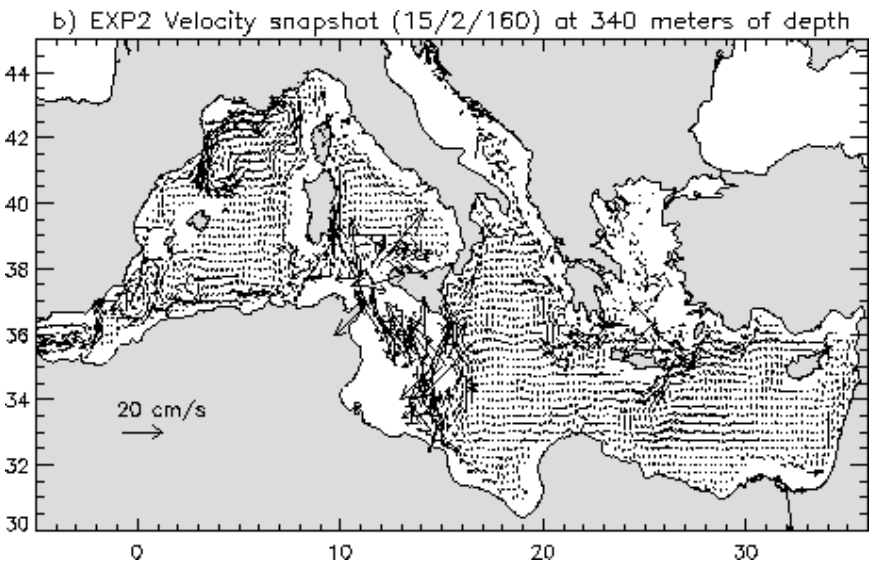

Fig. 8. The Mediterranean currents as may be shown by the Environment and Drifter Simulator (EDS) of the HCI.

- control statements to make tests on status variables (as "If ...Then") and take simple decisions in according to values of temperature, pressure, $\mathrm{pH}$, geographic position, time, etc;

- instrument statements to control the scientific payload.

The Integrated Development Environment (IDE) for ROV (and buoy) programming Fig.6.

This set of commands may be used in a IDE as well as the relative graphic set of commands may be used in the linked Visual Design Environment (VDE) that shows a graphic section of the sea (Fig. 5).

The VDE works in conjunction with an Environment and Drifter Simulator (EDS) that, if the environmental information is enough, let foresee the real behaviour of the drifter in the deep water and plan missions with high probability to do safely the survey. In such system the mission simulation is object of improving every buoy emersion by recalculating the remaining mission following the process in Fig. 7. The model data are periodically downloaded from National and European projects (as MFSPP - Mediterranean Forecasting System Pilot Project, MODB The Mediterranean Oceanic Data Base, SINAPSI - Seasonal, Interannual and decAdal variability of the atmosPhere, oceanS and related marIne ecosystems etc.) and integrated with buoy model and its programs.

At every cycle, with the current position of the buoy, the VDE shows the updated environmental model (example in

Fig. 8), recomputes its likely course and lets the pilot/scientist to modify accordingly the programs.

To get this it is necessary that buoy can contact the pilot/scientist anywhere he is. For this reason the HCI is mobile and the link with the buoy is made through a server station. Naturally the system must operate also if the connections aren't possible, so the HCI server is provided of capability to take decision about mission continuation (in

Fig. 9) playing the role of mission control system.

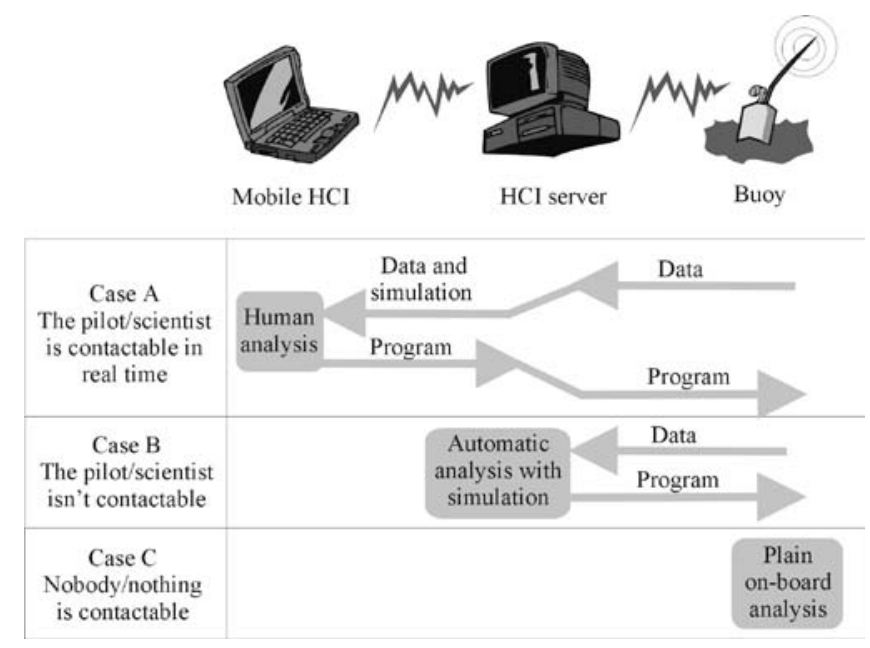

Fig. 9. The HCI accessibility by the buoy.

\section{DISCUSSION AND CONCLUSIONS}

The very innovative element of the project is the realisation of a buoy able "to follow" one of the parameter (density, salinity, temperature, deep of the body-of-water) calculated from the measurements performed by one of its own sensor. For example it is possible to keep the buoy adrift position in a body-of-water at constant temperature.

Bi-directional communications performed by the buoy itself are another innovative element implemented in MELBA project. The buoy will have the possibility to transmit data (for example for the speed download of the measured data) as well as to receive orders (for example a new set of the program instructions) from the terrestrial station or from the supporting marine station.

The final goal of the MELBA project is the realisation of a low cost multi-mission instrument, easy according to specific activities, still to be considered expendable, if used in open sea activity, but with a very high probability of recovery in local areas, with a communication channel and a positioning system allowing for easy collection of large amount of data well geo-referenced.

Such a drifter could be efficiently used also at the level of local administration, for periodical survey in restricted coastal areas.

For this kind of application the concept of expendability has to be revised, and also the data collection and transmission capacity has to increase, leading to the application of bi-directional high speed communication link, which will allow also for easy re-programming of the mission or easy retrieval of MELBA at the natural or forced end of the mission. 


\section{ACKNOWLEDGEMENTS}

In particular we want to acknowledge the following institution:

- CNR - IAN Italian National Council of Research Institute of Naval Automation.

- Idromar s.r.l. (www.idromar.it)

- Tecnomare S.p.a.

\section{GLOSSARY}

ARAMIS Advanced ROV package for Automatic Mobile Investigation of Sediments; an EC MAST III project

EDS Environment and Drifter Simulator;

ENEA Italian National Agency for New Technology, Energy and Environment;

EU European Union;

GPS Global Position System;

HCI Human Computing Interface;

IDE Integrated Development Environment;

MELBA MEditerranean Lagrangian Buoy Appliance

MFSPP Mediterranean Forecasting System Pilot

Project,

MIUR Ministry of Education, University and Scientific and Technological Research

MODB The Mediterranean Oceanic Data Base,

ROV Remotely Operation Vehicle

SINAPSI Seasonal, Interannual and decAdal variability of the atmosPhere, oceanS and related marIne ecosystems

VDE Visual Design Environment

\section{REFERENCES}

[1]. A. Terribile and other, “ARAMIS: a system for robotic inspection of sediments"- Conference Proceedings Oceanology International 2000, Brighton (UK),7-10 March 2000.

[2]. D. Maffei, B. Papalia, G. Allasia, F. Bagnoli, “A computer interface for controlling the ROV mission in scientific survey”, Conference Proceedings Oceans 2000, Providence (RI),11-14 September, 2000.

[3]. EU-MAST Project, http://www.cineca.it/mfspp/

[4]. EU-MAST Project, http://modb.oce.ulg.ac.be/

[5]. Italian-MIUR Project, http://sinapsi.cineca.it/

[6]. V.Rupolo, A. Babiano, V. Artale, D. Iudicone "Horizontal space-time dependent tracer diffusivity parameterization for a OGCM. A sensitivity study in the Mediterranean Sea” 